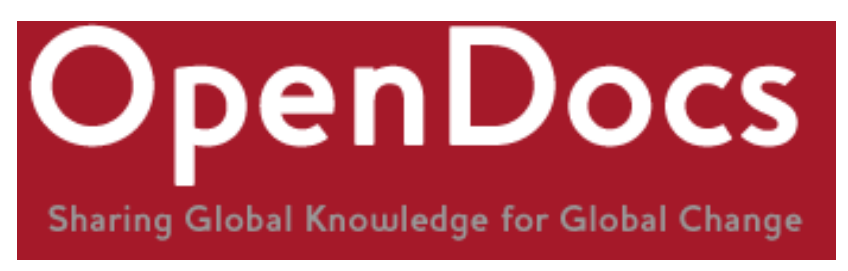

Title: Depleting tropical forest at a landscape scale: finding solutions for Bangladesh.

Citation: Sunderland, T.C.H., Kibria, M.G., Rahman, S. A. and Imtiaj, A. (2011) Depleting tropical forest at a landscape scale: finding solutions for Bangladesh. Journal of Biodiversity and Ecological Sciences, vol. 1, no. 1, pp.53-64.

Official URL: http://www.cifor.org/library/3358/depleting-tropical-forest-at-a-landscape-scalefinding-solutions-for-bangladesh/

More details/abstract: Drastic deforestation is a major problem of Bangladesh which is contributing to negative downstream impacts on the environment. To address this problem various measures should be taken at different scales. The main objective of this paper is to suggest the possible steps that Bangladesh could take and reverse the trend of deforestation. An extensive literature review and interviews with government officials, professionals and NGO workers have been used to collect relevant information on the agents of deforestation in the country. Based on the information gathered, this paper presents the reasons for the extent of deforestation, and suggests some positive steps where the Government could be the main mitigating actor by implementing integrated programmes, which will also ensure mass awareness and wider impact. Local NGOs and international bodies must also formulate adequate plans to protect valuable areas of remaining forest.

Version: Published version.

Terms of use: This work has been licensed by the copyright holder for distribution in electronic format via any medium for the lifetime of the OpenDocs repository for the purpose of free access without charge. This journal provides immediate open access to its content on the principle that making research freely available to the public supports a greater global exchange of knowledge.

This is a download from OpenDocs at the Institute of Development Studies

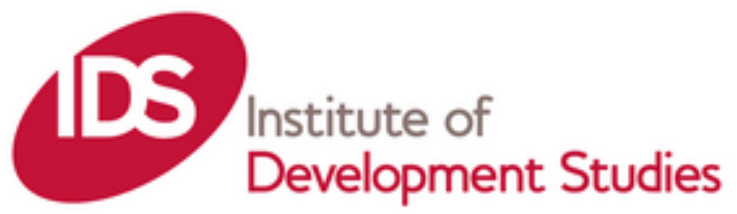


Original Article

\section{Depleting Tropical Forest at a Landscape Scale: Finding Solutions for Bangladesh}

T. Sunderland ${ }^{1}$

M. G. Kibria ${ }^{2}$

S. A. Rahman ${ }^{3 *}$

A. Imtiaj ${ }^{4}$

1-Center for International Forestry Research (CIFOR), Bogor Barat 16680, Indonesia.

2-University of Information Technology and Sciences (UITS), Rajshahi Campus, Rajshahi 6000, Bangladesh.

3 -*Poverty Environment Network (PEN), Center for International Forestry Research (CIFOR), Bogor Barat 16680, Indonesia; and Department of Sociology, University of Rajshahi, Rajshahi 6205, Bangladesh. 4- Department of Botany, University of Rajshahi, Rajshahi 6205, Bangladesh.

T.Sunderland@cgiar.org
Received Date:Dec/8/2010

Accepted Date:Jan/27/2011

\begin{abstract}
Drastic deforestation is a major problem of Bangladesh which is contributing to negative downstream impacts on the environment. To address this problem various measures should be taken at different scales. The main objective of this paper is to suggest the possible steps that Bangladesh could take and reverse the trend of deforestation. An extensive literature review and interviews with government officials, professionals and NGO workers have been used to collect relevant information on the agents of deforestation in the country. Based on the information gathered, this paper presents the reasons for the extent of deforestation, and suggests some positive steps where the Government could be the main mitigating actor by implementing integrated programmes, which will also ensure mass awareness and wider impact. Local NGOs and international bodies must also formulate adequate plans to protect valuable areas of remaining forest.

Key-words: lichens, bioindicators, atmospheric pollution, environmental health.
\end{abstract}




\section{Introduction}

Forest statistics in Bangladesh is anybody's guess; a real number in percentage for the forest area is hard to come by. The National Forest and Tree Resources Assessment 2005-2007 classified approximately $10 \%$ of the surface area of the country under forest [1]. The validity of the statistics remains questionable. Available data suggests that $90 \%$ of Bangladesh's forestry are lost or degraded due to the various pressures of a growing population (with an already existing base of 162 million people), development interventions, gaps in policy and legislation, and conflicting institutional mandates $[2,3,4)$. The protected area network of the country represents $1.4 \%$ of the surface area, one of the smallest proportions of protected forest in the world. Even though the current deforestation rate is low (less than 1 percent), Bangladesh is at a major risk of losing its forest resources and biodiversity unless the trend is reversed [5].

One eighth of the country's land area is affected by deforestation due to land clearances for agriculture, principally through shifting cultivation in the hill forests [3]. Other causes of forest loss include forest land encroachments, grazing, fire, uncontrolled commercial and subsistence logging, and fuel wood collection [6]. While existing forest cover is lost on a large scale, there are very small gains by afforestation of denuded areas and newly accreted land. Local wood supply cannot keep up with the demand for raw materials resulting in shortages and increased use of imports. Biomass fuels are predominantly used in household cooking. Outdated inefficient technology is evident in forest resource harvesting and manufacturing, resulting in unnecessary wastage.

In this context, forest should recieve special attention from the government, and the people should be more concerned. Each and every country requires one fourth of her surface area under forest, which is congenial to ecological balance. But Bangladesh is far short of this equation. To arrest or at least to minimize the processes and drivers of deforestation, mass awareness should be taken into serious consideration. The multifaceted importance of forest in the lives of the country's inhabitants and the danger of deforestation should be well publicized and to build up of public awareness, as well as adoption of serious different measures should take by the government, NGOs and other social organizations, should be in order.

The core objective of this paper is to suggest that awareness measures against drastic deforestation, could halt and reverse the trend of deforestation in Bangladesh.

\section{Material and Methods}

Content analysis and interviews have been used for this study. For content analysis, different types of government and 
nongovernment literature were used to obtain relevant information related to deforestation. In addition, interviews with government officials, other professionals and NGO workers have been used to elicit their experience and vision about the main reasons for forest depletion in Bangladesh as well as prospective management prospects.

\section{Results and Discussion}

\section{Extent and Reason of Deforestation}

Bangladesh's natural forests are controlled by the government Forest Department and fall broadly under three main classes: hill forests, inland deciduous Sal forests, and the Sundarbans mangrove forests. Inventories show an overall depletion in forest stocks in all the major forests [1]. However, the net deforestation rate is more severe than the official statistics suggest. It is very difficult to estimate the real picture indeed.

\section{Hill Forests}

This type of forest is tropical moist evergreen and semi-evergreen in nature and occurs in the greater Chittagong, CHT and Sylhet region and comprises roughly $38.2 \%$ of the country's total forest [1]. The main species represented are in the family Dipterocarpaceae and its associates including also a portion of plantation species. The main causes of depletion of hill forest are shifting cultivation and sustained over-exploitation. A system of clear felling followed by artificial regeneration has been practiced in the hill forest for long period and these areas were not replanted with adequate management and silvicultural practices in place. The establishment of plantations is problematic in the clear felled areas due to encroachment of the land for agricultural conversion, particularly swidden agriculture by minority and other ethnic groups, human habitation and livestock grazing. [7, 4]. The international boundary between Bangladesh and Myanmar is in this hill forest area and the Rohynga refugees of up to 1 million were forced to take shelter in the hill forests area in the early 1990 's due to military oppression in that part of Myanmar adjacent to Bangladesh. The United Nations High Commission for Refugees is working to repatriate them to Myanmar and an estimated quarter of them have already returned. In the meantime, the result of the slow negotiation process is the consequential scale of destruction of a large part of the forest due to shifting cultivation and timber extraction. This has put added fuel to fire of destruction which was already undertaken previously by local illegal timber traders.

\section{The Sal (Shorea spp) Forests}

The Sal forests fall under the tropical moist deciduous forest class (greater Dhaka, Mymenshing, Tangail, Rangpur and Dinjapur region) which constitutes about $2.3 \%$ of the total forest [1]. Considerable forest destruction occurred during the liberation war 
of Bangladesh in 1970 in the country as a whole and particularly in the Sal forests. The natural Sal forests were previously managed by clear felling for timber followed by coppice regeneration. The Government banned the felling process realizing the fact that the forest had degraded due to excessive felling and coppicing. But the law was unable to protect this natural deciduous forest. these central and northern part of the country are the most densely populated and the main cause of the depletion of these forests was due to land clearance for agriculture and forest land encroachment. More than half of the total Sal forest has already been depleted. The remaining patches are in poor condition, degraded and in the process of being lost. Some measures by the government and also non-governmental organizations were taken to involve farmers in forestry i.e., agroforestry and community woodlot plantations. However, this was ineffective in halting the deforestation process and encroachment. Arguably due to the negligence and corruption of the government forest department staff and the extended support of the local political leaders to those responsible for encroachment. Recently, another problem has been cited that the farmers who participated in the community forestry programs are not getting their share from the harvesting of the timber crop. Initially all shareholders agreed to the program that the profits will be distributed to them according to an agreed predetermined ratio. However, due to lack of proper management and prompt response from the government FD when the plantations have reached to the harvesting age for the first rotation, the farmers stopped looking after the plantations. Mature trees are now being felled and taken away by the illicit loggers taking this opportunity due to the inactivity of farmers. Once the trust of the farmers is lost, then it will be very difficult for government FD to regain and hope to implement this type of participatory approach of forestry practice in future.

Encroachment and illicit removal of timber and firewood from the forests are the major forest conservation problems in the area. The Sal forests are under constant human pressure from all sides as there were no boundaries or demarcations off the forest. The forests are in patches, intermingled with private agricultural lands and habitations encircling that small block of forest. The areas under encroachments estimated about 0.036 million ha and the number of encroachers are about 100,000. The chief reasons of encroachments are: legal lacunae due to past tenurial history of the lands, and intricate nature of the boundary of the forest land an cultivable lands, and failure to complete the forest settlement operations initiated in the 1950 's. The main reasons for illicit removal of timber are: wide gap between the demand 
and supply of wood and its consequent high prices (illicit removal of even a head-load of firewood turns out to be more lucrative than a day's wage of rural labourer, removal of timber and poles is even more lucrative); limited year round employment in rural areas resulting in compelling dependence on the collection of wood from the forests for subsistence; existence of organized groups who professionally indulge in illicit cutting and removal of valuable trees of the forests [1].

Most of the Sal forests are now severely degraded and poorly stocked. Some three decades ago, more than 60 percent of these forests were fairly densely wooded. But today, the forest has been reduced both in extent and tree density as well as stand quality. These are, in fact, the worst hit of all the forests in the country. FAO estimated that about 36 percent of the forest cover existed in 1985; more recent estimates (2005) suggest that only about 6.7 percent of the forest cover remains [5]. Despite a moratorium imposed in 1972 on extraction of wood from Sal forests, illicit felling has continued unabated.

\section{The Sundarbans Mangrove forests}

The Sundarbans is the largest single tract mangrove formation in the world. The main species is Sundri (Heritiera spp.) and other associated mangroves whose main species belongs to Rhizophoraceae family (Sonneratia spp., Excoecaria spp., Xylocarpus spp., Ceriops spp. etc.). The forest is fully controlled and managed by the Government Forest Department. The area is legally declared as a Reserve Forest so there is no human habitation and locality inside the forest except some people inhabiting the periphery. The Sundarbans constitute about 30.2 percent of the natural productive forests of the country [1] and provide livelihood for at least 0.5 million people who are mainly wood cutters, fisherman, honey collectors and Nypa palm leaf (fronds) [locally known as Golpata] collectors, Phoenix paludosa (hental) collectors, shell collectors and fishermen [1]. Beside forest resources, the Sundarbans forest is extremely important for fish production, wildlife conservation and, recreation which serve as a protective barrier against coastal erosion, cyclones, storms and tidal surges. The mangrove forests and mudflats of the Sundarbans provide the vital breeding and nursery grounds for a large proportion of the fin fish, crustaceans and mollusks harvested. The significant depletion of the growing stock, notably of Heritiera (Sundri) and Excoecaria (Gewa) which appear to have been reduced by $40 \%$ and $45 \%$ respectively between 1959 and 1983. The incidence of crown death of Heritiera spp seems to be increasing with rapid ecological changes rendering the site unsuitable for the species. The lack of experienced and trained staff, inadequate data base and, accessibility are also the main problems to properly manage the forest [8]. 
The main reasons of the depletion for this forest are due to improper and poor management, over exploitation and, to some extent, ecological reasons. For example, the construction of the Farraka barrage over the upstream of the Ganges by India in West Bengal, reduced the water flow significantly during the dry season which increased the salt intrusion from the sea and disturbed/changed/altered and modified the ecosystem. The causes of the $40 \%$ or moredying of the main species Sundri (Heretiera spp) is still partially known [8, 9]. The depletion of this mangrove forest should be stopped immediately due to its ecological significance. Recently, the Sundarbans mangrove forest (an important habitat for the Bengal Tiger) has been declared as a world heritage site by the UNESCO. This should encourage the Government of Bangladesh to take necessary steps to protect and reserve this unique and dynamic yet fragile and complex ecosystem.

\section{Consequences of Forest Destruction in}

\section{Bangladesh}

The major consequences of the deforestation that, presently Bangladesh is facing, is seriously affecting the economy of the country. The effects of uncontrolled logging are most destructive in the hilly areas [7]. Because of that reason, landslides and soil erosion have increased significantly. Soil degradation in the plain lands due to nutrient deficiency is also common. Previous natural nutrient cycling from the forest to the plain arable lands has been destroyed by clearing the forest and afterwards using large quantities of chemical fertilizers and uncontrolled use of the hazardous toxic pesticides [4]. The dose of the chemical fertilizer application is increasing every year resulting in infertile, barren soil. Land degradation is accelerated by this process. Also the devastation after the cyclones and storms in exposed areas to the bay near the coastal lines is now more severe than the past. The situation is becoming worse as the time passes.

\section{Remedies}

In fact, there is a great deal of scope for forestry in Bangladesh. Comprehensive planning is required to utilize the Unclassed State Forest (USF) land (which is virtually barren and unproductive), marginal and waste land, homesteads, roadside lands and railway side, embankments, pond banks, canal and river banks, institutional premises etc. These lands can be planted with multipurpose tree species, which may provide significant alternative sources of forest produce and timber and can help to reduce the pressure on the remaining natural forests. Despite the shortages of skilled forestry personnel, the Green-Belt project by the FD to restore the coastal lands is a promising approach. Forestry graduates from universities of the 
country can be appointed to implement this type of program effectively.

The major causes are more or less similar for the depletion of all the forest types. In some cases, all these causes are affecting and operating simultaneously, making the situation worse. Without the firm commitment of the government to stop the forest depletion, probably little or no change will occur. In general, motivation, awareness creation among the general public, updating and enforcement of laws, employing trained, honest and efficient manpower equipped with forestry knowledge may be some of the much-needed remedial measures.

Developing awareness regarding deforestation and forestation programme is not systematic and well co-ordinated. Without the inter-ministerial effort and co-ordinated programmes, rate of deforestation cannot be checked. However, the government is not particularly concerned about the long-term impacts of deforestation. It is noteworthy that the Bangladesh Bureau of Statistics, under the Ministry of Planning, in its Statistical Pocket Book of Bangladesh, 2008 has furnished considerable statistical information, but there is almost no information regarding forest loss. Environmentalists and organisations as well as people working in this field try to draw the government's attention towards the menace of the deforestation as well as the development of reserve forests and in addition to the development of the awareness toward agroforestry. To make the progress a success government's, positive and potential participation is essential, but unfortunately it is negligible.

\section{Different Awareness Measures}

a) Government Measures

Government may take different measures to make the people understand the importance of afforestation and the menace of deforestation. It is easier for the government to use its different machineries more widely and effectively. The Government can use the remits of the Ministry of Agriculture, Ministry of Forest, Ministry of Education, and Ministry of Information for wider publicity in favour of afforestation. Inter-ministerial integrated programme should be taken to develop the knowledge and awareness of the people regarding the hazards of deforestation. To protect and develop the country's forest resources integrated inter-ministerial programme is an urgent need.

Ministry of Agriculture and Ministry of Forests: To check the deforestation programme and to make it a success, these two ministries should work together in an integrated way. If the government desires, the Ministries of Agriculture and Forestry can prepare co-ordinated programmes for afforestation and to cease deforestation of the country. The following programmes may be conducted:

In rainy season`s, both ministries should try to supply saplings, manure, 
booklets and other materials to the villagers and interested persons at absolutely minimum price. The ministry should run a campaign that to the effect at least five saplings of the same species should be planted prior to cutting a tree for economic reasons. To make the campaign viable, along with the materials of forestation they will also supply booklets, posters, hand bills, leaf lets, free of charge to promote awareness among the people regarding the multifarious environmental risks of deforestation.

The Ministry of Forest can arrange training programmes for different types of agro-forestry. Those who have no extra land can grow homestead forest or cropland agroforestry. Bangladesh has a long history of homestead tree cultivation with species such as mango, lychi, guava, blackberry, coconut etc. These tress give lucrative fruits and after a long duration, these are disposed of as timber for furniture and other house building works. In addition to these, there are some special trees such as mahogany, Dalbergia sisso, the sal tree (Vatica robusta), teak, and silk cotton tree etc which are sold as timber at a high price. It strengthens the family economy and country as well. But early deforestation has ruined both the environment and economy. In this regard data may be furnished which is discouraging for the interest of the country. The following Table-1 shows us a hopeless scenario of our forest products. The production of timber and fire wood in 2005-2006 has declined in comparison to 2004-2005.

Ministry of Education: The Ministry of Education can also play a vital role in making people understand the importance of forestry which is a dominant factor in the social, economic and environmental upliftment of the country. The Ministry of Education could include matters related to forestation and deforestation in the curriculum of schools and colleges.

At the primary level, the importance of trees may be included in the syllabus such as: trees give us oxygen, it gives us shade, gives us fruits, gives wood for different household purposes. At the junior level: how trees are planted and nursed and how it creates environmental balance. Practical and demonstration classes may be arranged regarding plantation and nursing of plants. Finally, at the high school level, the advantages of forestation and the demerits of deforestation may be taught. At a higher level, forestry as a subject may be included in the syllabus. Moreover, the Ministry of Education should be seriously concerned about the menace of deforestation. Education Ministry can arrange training programmes for the agricultural labour regarding afforestation, and how that could be expedited. In addition to that, the ministry may also arrange constant campaign against wide spread deforestation. 
The Ministry of Education may as well arrange training programmes for the teachers to develop their knowledge and awareness regarding the dangers of deforestation and benefits of forestation. Later on, teachers may relate their knowledge to their students. In the rural areas, school and college teachers can help develop mass awareness as they are very much respected in the wider society.

The Ministry of Information may play an important role in propagating the divesting effects of deforestation and the need of forestation in the economy and environmental balance of the country. This publicity may be undertaken by collecting data and information from the field level. Without accurate data policy makers cannot make the potential decisions to address the problem. The Country should know of the progress of forestation and the rate of deforestation accurately. In this regard, the Ministry of Information may play a key role as media facility is available to them. The ministry may take a consolidated propaganda programme regarding the matter.

The Department of film and publication may also play on essential role to develop the mass awareness regarding the dangers of wide scale deforestation in Bangladesh which may affect economy as a whole and environmental balance in the long run. This can be propagated in the following way: i.by distributing leaflets

ii.printing and displaying posters

iii.preparing and showing documentaries especially in the rural areas

iv.publishing and distributing free of cost booklets

v.arranging funds for distributing seed and seedlings at a cheap rate; also hand bills free of cost building awareness against deforestation.

b) NGOs: Good numbers of non-government organisations (NGO) are working in different fields, to develop the country. NGO's are working in the field of education, micro credit, water supply, sanitation, healthcare, forestry etc. There are also some NGOs working in afforestation programmes. The government may patronise the NGOs to include mass awareness programmes regarding deforestation throughout the country.

c) Private Initiative: At a private level, there are many villagers interested in agroforestry. Now many people are doing cropland agroforestry by their own initiative as they have realized its benefits. There is a growing evidence of planting trees with crops, because commercial thinking has been developed among the village people. They need only some government and NGO support and cooperation, because initial investment is required for agroforestry cultivation and many poor farmers do not have money to invest. 
Public and private plantation programmes should be undertaken in the barren hilly areas and clear felled areas immediately. The most successful story of FD may be demonstrated like the Betagi Community Forestry model farm as in the hill forest areas of Chittagong. Landless labourers, farmers, encroachers, illicit loggers were selected and given about 2 hectares of land to each on a leasehold basis. They were also given an initial loan for raising the tree plantations. Periodic repayments of the loan was ensured. The incomes of the farmers had increased from US\$70 to US\$1600 per year after seven years of the practice, which has been shown in several studies. In a similar fashion, the hill forest may be recovered again by selecting the individuals based on some well accepted criteria i.e., poverty, gender, regular loan repayment etc. Segments of the poor, destitute women, landless labourers, small co-operatives, medium entrepreneurs may be the target client groups.

\section{Conclusion}

Forest is particularly important in the context of present environmental degradation and ecological purposes of Bangladesh. Developing mass awareness regarding afforestation is the crucial need of the present time. Attempts should be taken to check wide scale deforestation of Bangladesh to save the economy of the country and maintain ecological balance. Along with the forestation campaign its large scale plantation should also be emphasized. This mammoth task cannot be done without the governments' active participation and inspiration. Inter ministerial efforts and co-ordinated programmes can bring positive results against large scale deforestation, and ensure wide scale forestation in the country. Along with the government efforts, NGOs could be included to bring fruitful results.

Conservation could be the potential alternative measure to conserve Sal forest. Enforcement of the law, forestry extension in the adjacent localities, motivation and campaign can stop further depletion of the forest. For the mangrove forests, specific policy is required by the government. The control of the Forest Department over the Sundarbans is still strong. This may be used for its proper management and conservation. Immediate steps should be taken to stop the over-exploitation of resources before complete deterioration of the administrative control of Forest Department over the Sundarbans.

Though there is a controversy but according to the forecast of the scientific community, the country will probably be severely affected by the green house effect, global warming and sea-level rise. Bangladesh needs world support to halt further deforestation and degradation of its small but very important valuable natural 
forests. There are very few alternatives to protect the environment except the conservation of forests and extension of forestry. The international bodies should formulate adequate plans before depletion of all forests and to conserve the forests, tropical forests in particular, around the whole world.

\section{Reference}

1. Bangladesh Forest Department (BFD), National Forest and Tree Resources Assessment 2005 - 2007, Bangladesh. Ministry of Forestry, Dhaka (2008), p.327.

2. Economic and Social Commission for Asia and the Pacific (ESCAP), ESCAP Population Data Sheet 2009. Population and Rural and Urban Development Division, Bangkok (2009).

3. S. A. Rahman, W. de Groot and D.J. Snelder, Exploring the agroforestry adoption gap: financial and socioeconomics of litchi-based agroforestry by smallholders in Rajshahi (Bangladesh), in D. J. Snelder and R.D. Lasco (eds.), Smallholder Tree Growing for Rural Development and Environmental Services: Lessons from Asia (2008) 227-244.

4. G. Rasul, G. B.Thapa and M. A. Zoebisch, Determinants of land-use changes in the chittagong hill tracts of Bangladesh. Applied Geography 24(2004) 217-240.

5. FAO, State of the World's Forests 2009. Rome, Italy (2009), P. 432.

6. Bangladesh Bureau of Statistics (BBS), Statistical Pocketbook of Bangladesh 2008. Ministry of Planning, Dhaka (2008) 212.

7. S. A. Rahman, M.F. Rahman, A.L. Codilan and K.M. Farhana, Analysis of the economic benefits from systematic improvements to shifting cultivation and its evolution towards stable continuous agroforestry in the upland of Eastern Bangladesh. International Forestry Review 9(1) (2007) 536-547.

8. IPCC (Intergovernmental Panel on Climate change), Land-use, Land-use Change and Forestry, Special Report. Cambridge University Press, Cambridge (2000), p. 34.

9. Bangladesh Agricultural Research Council (BARC), Land Degradation Situation of Bangladesh. Soil Science Division, Bangladesh Agricultural Research Council, Dhaka (1999), P. 67. 
Table 1: Output of Some Selected Forest Products (Reserve Forest)

\begin{tabular}{cccccc}
\hline Items & Unit & $2002-03$ & $2003-04$ & $2004-05$ & $2005-06$ \\
\hline Timber & $‘ 000 ’ \mathrm{cft}$. & 2669.97 & 3606.32 & 5216.04 & 3324.37 \\
Firewood & $‘ 000 ’ \mathrm{cft}$. & 6958.56 & 4645.75 & 6638.89 & 3117.15 \\
Bamboos & $‘ 000 ’$ nos & 57604.32 & 15741.58 & 57051.73 & 68280.98 \\
\hline
\end{tabular}

Source: [1]

\section{Journal of Biodiversity and Ecological Sciences}

